\title{
Is the Centralized Treatment of Small Cell Carcinoma of Anal Canal Necessary? A Case Report
}

Pablo Menéndez ${ }^{1 *}$, Lorenzo Rabadán ${ }^{2}$, Pedro Villarejo², David Padilla² and Ricardo Pardo²

General Surgeon, Hospital Gutierrez Ortega, Valdepeñas, Ciudad Real, Spain

General Surgeon, Hospital General de Ciudad Real, Ciudad Real, Spain

\begin{abstract}
Anal canal tumor has different prognosis depending on the histological type. Cancer of the anal canal is an uncommon condition in digestive tumors, representing small cell cancers of the anal canal less than $0.2 \%$ of all colorectal tumors. The histological type of tumors of the anal canal will determine treatment and prognosis. We report the case of a male aged 71 who presented with rectal bleeding and constipation. It revealed a tumor $2 \mathrm{~cm}$ from the anal margin, with pathological diagnosis of small cell undifferentiated carcinoma. Despite treatment with chemotherapy and radiotherapy, the disease progressed to develop multiple metastases, and the patient died due to pulmonary thromboembolism and multiorgan failure. Centralized management of these tumors would allow the creation of specific guidelines for treatment and follow-up with the aim of achieving better morbidity and mortality rates.
\end{abstract}

Keywords: Anal canal cancer; Small cell carcinoma; Oat-cell carcinoma

\section{Introduction}

Anal canal cancer is a rare disease with a variable survival depending on histological type. Diagnosis and treatment of anal cancer depends on the tumor histology and the anatomic location. We report the case of a patient with small cell carcinoma of anal canal showing the aggressiveness of these tumors.

\section{Case Report}

We present a case of a 71-year-old man with a history of brucellosis in childhood and smoking. Due to a rectal bleeding associated with constipation of recent onset, a colonoscopy was performed, showing a thickened fold 1-2 cm tumor of about $2 \mathrm{~cm}$ from the anal margin. Histopathological examination revealed a small cell undifferentiated carcinoma. Analytically, CEA was $3.9 \mathrm{ng} / \mathrm{mL}$, and CA 19.9 was $11.7 \mathrm{U} /$ $\mathrm{mL}$, with no other alterations. Transanal endoscopic ultrasound showed a tumor exceeding the muscularis mucosae; the computed tomography (CT) revealed a rectum tumor without involvement of the surrounding spaces; magnetic resonance imaging (MRI) showed an irregularity of the right posterolateral wall of the anal canal about $3 \mathrm{~cm}$ above the levator ani muscle and lateral adenopathy above the level of the tumor (Figure 1). Microscopically, the tumor showed undifferentiated small cells arranged in solid nests. Immunohistochemically, positive stains were detected for NSE, CK-AE1/AE3, EMA, synaptophysin, chromogranin-A, and negative for CEA, CK-20, CD45, S100 and vimentin (Figure 2). Finally, the diagnosis was small cell carcinoma of anal canal (T2N1, IIIA). After the diagnostic process, chemotherapy with topotecan and cisplatin simultaneous with radiotherapy (reaching a dose of 45Gy), was started.

Six months later, a brain CT showed a $15-\mathrm{mm}$ solid nodule with surrounding edema at the front left region, one left parietal nodule of $7 \mathrm{~mm}$ and one left occipital nodule of $13 \mathrm{~mm}$ with edema (Figure 3). It was decided to give holocranial radiotherapy in ten sessions, being the final dose of $30 \mathrm{~Gy}$. After radiotherapy, a MRI control showed the presence of multiple brain metastases.
The abdominal CT, after radiotherapic treatment, detected three hypodense enhanced lesions, the biggest one with $14 \mathrm{~mm}$ diameter; at the right adrenal gland a nodular enhanced image of $2 \mathrm{~cm}$ of diameter suggestive of metastasis was showed. At the rectum multiple locoregional lymph nodes were observed.

Following abdominal imaging study, an increase in the number of liver lesions, multiple peritoneal implants, lymph nodes at the retroperitoneum and ascites were showed. Given the progression of the disease, further treatment was rejected. Eleven months after the clinical onset of rectal bleeding, the patient died of a pulmonary embolism and multiorgan failure.

\section{Discussion}

Anal canal cancer is an uncommon disease because it represents 1.2$2 \%$ of gastrointestinal tumors, and $6 \%$ of ano-rectal tumors, with more than two thirds of cases over 65 years [1-3]. Squamous cell carcinoma is the most common histological type reported (60-80\%); other types such as adenocarcinoma, small cell carcinoma, undifferentiated carcinoma, sarcomas, lymphomas and melanomas have been described; the anal canal small cell cancers represent less than $0.2 \%$ of all colorectal tumors $[1,4]$. The risk factors associated with anal canal tumors are female sex, age, homosexuality, HIV infection, HPV infections, tobacco, anorectal disorders or chronic immunosuppression [1,3-6].

Three histologic types of small cell carcinoma of colorectal region are described: the undifferentiated small cell carcinoma (small tumor

*Corresponding author: Pablo Menéndez Sánchez, General Surgeon, C/ Julio Palacios 29, Esc. B. 7B. 28029. Madrid. España, Spain, Tel: +34 660333 554; E-mail: pablomensan@hotmail.com (or) pablo.menendez.sanchez@gmail.com

Received June 29, 2011; Accepted September 10, 2011; Published September 22, 2011

Citation: Menéndez P, Rabadán L, Villarejo P, Padilla D, Pardo R (2011) Is the Centralized Treatment of Small Cell Carcinoma of Anal Canal Necessary? A Case Report. J Cancer Sci Ther 3: 158-160. doi:10.4172/1948-5956.1000080

Copyright: ( 2011 Menéndez P, et al. This is an open-access article distributed under the terms of the Creative Commons Attribution License, which permits unrestricted use, distribution, and reproduction in any medium, provided the original author and source are credited. 
Citation: Menéndez P, Rabadán L, Villarejo P, Padilla D, Pardo R (2011) Is the Centralized Treatment of Small Cell Carcinoma of Anal Canal Necessary? A Case Report. J Cancer Sci Ther 3: 158-160. doi:10.4172/1948-5956.1000080

cells and scanty cytoplasm), neuroendocrine carcinoma (larger tumor cells and abundant cytoplasm) and stem cell carcinoma (transitional type between the previous) [4].

Small cell carcinoma is seen most prevalent in the lung, and may also appear in skin, kidney, thymus, pancreas and gastrointestinal tract, where the esophagus is the most frequently described, followed by the rectum, cecum and sigmoid colon [3,4]. The clinical symptoms from the digestive location is bleeding, pain, palpable mass, hemorrhoids, weight loss or pruritis, with a median time from symptom onset to diagnosis of three months [7].

The diagnostic process should include complete physical examination, proctosigmoidoscopy, CT and/or MRI, endoscopy and biopsy $[5,7,8]$. The histopathology of small cell carcinoma of anal canal is characterized by positive immunohistochemistry of synaptophysin, chromogranin, cytokeratine and neuoron specific enolase (NSE) $[4,9]$.

The combination of radiotherapy and chemotherapy is the treatment of choice for anal canal tumors $[1,5]$. The main objective is the local control and preservation of anal sphincter function [5,7] It has been shown that chemotherapy has higher response rate to 5 -fluorouracil combined with cisplatin or mitomycine [1,8]. Good response to conservative treatment must reach a dose of $45 \mathrm{~Gy}$ at anal
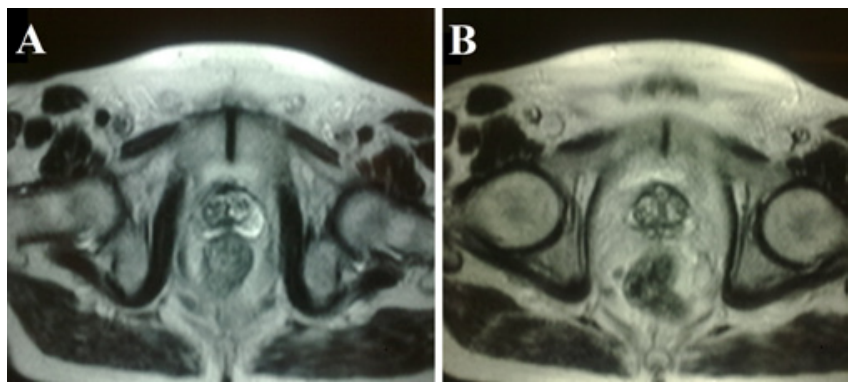

Figure 1: A. Magnetic resonance imaging which shows an irregularity of the right posterolateral wall of the anal canal about $3 \mathrm{~cm}$ above the levator ani muscle. B. Lateral lymph node located right above the level of tumor.

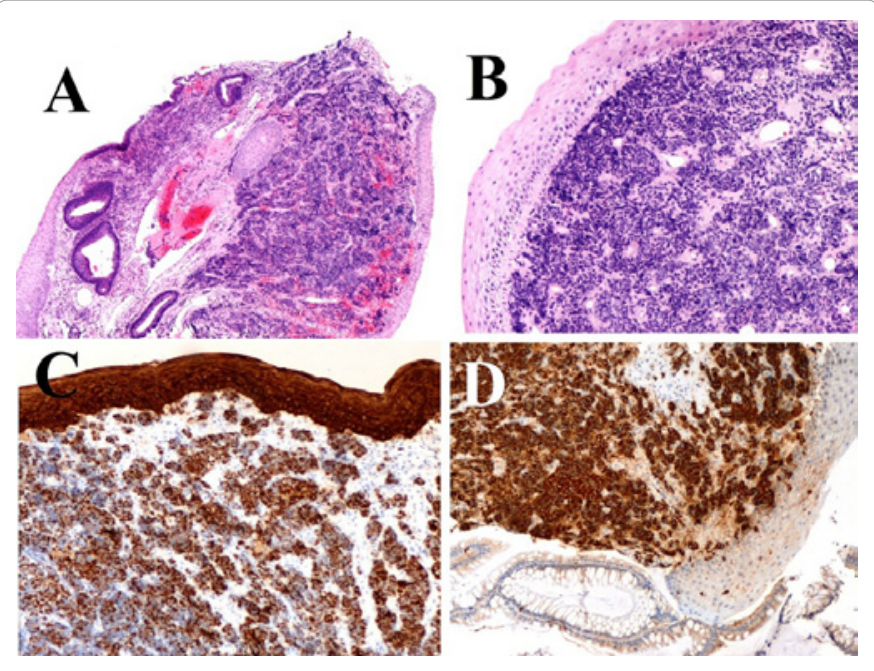

Figure 2: A, B. Anal canal small cell carcinoma (HE 20X and 200X, respectively). C. Immunostaining for cytokeratin 2. D. Immunostaining for synaptophysin.

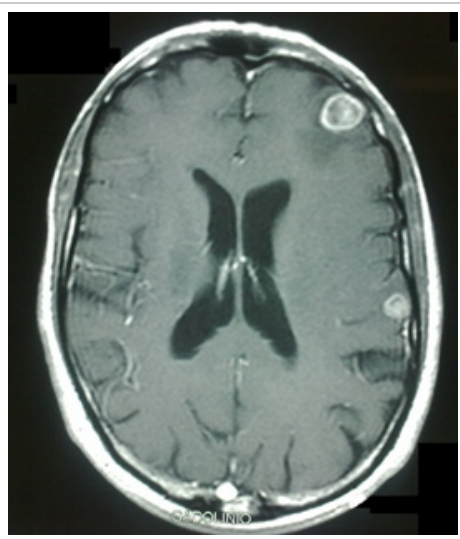

Figure 3: Brain computed tomography showing a solid nodule of $15 \mathrm{~mm}$ with perilesional edema at the front left region, and a parietal superficial nodule of $7 \mathrm{~mm}$.

canal and mesorectum lymph node involvement (perirectal, internal iliac, inguinal and presacral); at primary tumor, radiotherapy must reach a total dose of 15-20 Gy [1,4,5,8]. Eight weeks after combined treatment, it must be necessary to determine the need of surgery; the surgical treatment of these tumors is reserved for patients with poor response to medical treatment, requiring the abdominoperineal amputation in situations of residual disease or relapse, defined as presence of disease in a period less than six months after multimodal treatment [5]. Surgery is also indicated in early stages that are associated with favorable histology whenever sphincter is respected and there is a resection margin at least of $1 \mathrm{~cm}$, although there is an increased risk of recurrence [2].

The prognosis is determined by stage and tumor size, lymph node involvement, age, radiation dose and overall treatment time $[5,7,8]$. The survival rate of anal canal tumors ranges from $79 \%$ for tumors less $4 \mathrm{~cm}$ without lymph node involvement, to $58 \%$ for tumors larger than $4 \mathrm{~cm}$ with lymph node involvement (five-year survival, T1: $94 \%$ T2: 79\% T3: 53\% T4: 19\%) [5]. Anal canal tumors have metastatic disease at diagnosis in 5\%, with an overall incidence of metastasis of $10-30 \%$; the most common sites are lung, liver, bone and brain, with a five-years survival rate of $18 \%[1,5,6]$. The aggressiveness of small cell tumors causes increased mortality to $42 \%$ at six months, and $94 \%$ at five years, partly due to the presence of distant metastasis and lymph node involvement between $70-80 \%$ at the time of diagnosis $[3,4,9]$.

The centralized treatment of these patients, would create the appropriate monitoring guidelines for this type of tumor, which should include a rectal examination, inguinal lymph nodes examination, sigmoidoscopy, and imaging tests such as CT and MRI [5].

\section{Conclusion}

Despite the small number of patients affected by carcinoma of the anal canal it remains one of the most challenging cancers to treat. Centralized treatment of anal canal neoplasms would allow the elaboration of clinical trials to determine the adequate treatment (chemotherapy and radiotherapy), and also the establishment of guidelines for monitoring these patients. 
Citation: Menéndez P, Rabadán L, Villarejo P, Padilla D, Pardo R (2011) Is the Centralized Treatment of Small Cell Carcinoma of Anal Canal Necessary? A Case Report. J Cancer Sci Ther 3: 158-160. doi:10.4172/1948-5956.1000080

\section{Acknowledgement}

To Margarita Lopez for her collaboration.

\section{References}

1. Fesneau M, Champeaux-Orange E, Hennequin C (2010) Anal cancer. Cancer Radiother 14 Suppl 1: S120-126.

2. Garrett K, Kalady MF (2010) Anal neoplasms. Surg Clin North Am 90: 147-161.

3. Brenner B, Tang LH, Shia J, Klimstra DS, Kelsen DP (2007) Small cel carcinomas of the gastrointestinal tract: clinicopathological features and treatment approach. Semin Oncol 34: 43-50.

4. Kosmidis C, Efthimiadis C, Anthimidis G, Vasiliadou K, Tzeveleki I, et al. (2010) Small cell carcinoma in ulcerative colitis new treatment option: a case report. World J Surg Oncol 8:100.
5. Eng C (2006) Anal cancer: current and future methodology Cancer Invest 24 535-544

6. de Jong JS, Beukema JC, van Dam GM, Slart R, Lemstra C, et al. (2010) Limited value of staging squamous cell carcinoma of the anal margin and cana using the sentinel lymph node procedure. A prospective study with long-term follow-up. Ann Surg Oncol 17: 2656-2662.

7. Balamucki CJ, Zlotecki RA, Rout WR, Newlin HE, Morris CG, et al. (2011) Squamous Cell Carcinoma of the Anal Margin. The University of Florida Experience. Am J Clin Oncol 34: 406-410.

8. Otto SD, Lee L, Buhr HJ, Frericks B, Höcht S, et al. (2009) Staging anal cancer prospective comparison of transanal endoscopic ultrasound and magnetic resonance imaging. J Gastrointest Surg 13: 1292-1298.

9. Ihtiyar E, Algin C, Isiksoy S, Ates E (2005) Small cell carcinoma of rectum: a case report. World J Gastroenterol 11: 3156-3158. 